\title{
A democracia e a universalização do Ensino Fundamental
}

\author{
Francis Mary Guimarães Nogueira ${ }^{1}$
}

Liliam Faria Porto Borges?

A divulgação do MEC em 2001 de que havíamos universalizado o Ensino Fundamental com o índice de ingresso e permanência de 96,3\% das crianças em idade escolar, e a repercussão política deste fato na academia, e em segmentos importantes de professores que militaram política e teoricamente em defesa da Universalização da Educação Básica nos anos 70 e 80, esteve marcada por um tom de frustração e desolamento. A reação expressou-se em publicações e palestras proferidas em fóruns educacionais, revelando a negação das estatísticas sobre as conquistas que viabilizaram a universalização. ${ }^{3}$

O questionamento ao dado estatístico sobre o percentual de crianças na escola de 7 a 14 anos, somou-se ao conjunto de críticas teóricas e contestações políticas que a esquerda já vinha fazendo, ao chamado pensamento (neo)liberal na educação nos anos 90. Tais críticas se pautam fundamentalmente na análise de que categorias e conceitos que haviam sido centrais na luta da esquerda nos anos 70 e 80 estariam sendo re-significados pelos neoliberais, na medida em que se transformou a defesa da participação da comunidade na escola em o "Dia da Família na Escola", a qualidade em qualidade total, a conquista democrática da descentralização administrativa e do financiamento em desresponsabilidade do Estado para com a educação, e a gestão

1 Professora Adjunta da Universidade Estadual do Oeste do Paraná-Cascavel. 2 Professora Assistente da Universidade Estadual do Oeste do Paraná-Cascavel.

3Marília Pinto Carvalho, "Estatísticas de desempenho escolar: o lado avesso". In: Educação e Sociedade, Campinas, v. 77, ano XXII, dez. 2001, pp. 231-252.

cadernos cemarx, $n ^ { 0 } 2 - 2 0 0 5 \longdiv { 7 7 }$ 
democrática em gestão compartilhada ou participativa. Nesse sentido essa crítica postula e reafirma que a "nova direita" ardilosamente teria se apropriado de nossas históricas bandeiras de luta, rearticulando esses conceitos na perspectiva (neo)liberal.

O que parece orientar teoricamente esses intelectuais de esquerda que se contrapõem energicamente ao pensamento (neo)liberal é a idéia de que o (neo)liberalismo, no seu conteúdo econômico-doutrinário, e nas suas estratégias políticas, seria antidemocrático, apesar de reconhecerem que este não tenha rompido com as regras da representatividade eleitoral, fundamento basilar da democracia liberal. ${ }^{4}$

A concepção de democracia reivindicada pelo movimento dos educadores indica que sua realização implicaria, no limite, em distribuição social do resultado do trabalho humano, ou seja, em justiça social. ${ }^{5}$ Em nosso entendimento a democracia moderna se expressa na representatividade pautada pela igualdade jurídica. Filha da lógica liberal e, portanto, construtora do projeto capitalista, a democracia na sua plena efetivação tem garantido a possibilidade do voto, da representatividade e de uma cidadania definida pela igualdade perante a lei. Temos então duas concepções sobre o que seja democracia e, este entendimento parece-nos definidor de práticas políticas distintas.

Para quem entende que a democracia só será possível numa sociedade igualitária, o (neo)liberalismo seria antidemocrático. Já para aqueles que concebem a democracia como uma categoria constituinte do projeto liberal, a partir da própria observação empírica do que ocorre no Brasil, o (neo)liberalismo não seria antidemocrático, pois ele não romperia com os seus pressupostos fundantes de igualdade jurídica e representatividade.

Na mesma direção e como conseqüência daquele precário e ambíguo entendimento sobre democracia, os neoliberais teriam "criado" como estratégia ideológica uma confusão semântica entre palavras com a mesma grafia, instaurando a polissemia entre vocábulos idênticos. Portanto, não demarcando para vocábulos iguais formulações teóricas, políticas e ideológicas distintas. Nesse sentido, a crítica da esquerda ao pensamento (neo)liberal indica que seria preciso disputar os conceitos, as categorias e, em última instância, o próprio entendimento dessas palavras idênticas em suas grafias, mas com

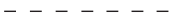

4 Gaudêncio Frigotto, "Os delírios da razão: crise do capital e metamorfose conceitual no campo educacional”. In: Pablo Gentilli, Pedagogia da exclusão: crítica ao neoliberalismo em educação. Petrópolis, Rio de Janeiro, Vozes, 1995, pp. 77-108.

5Pablo Gentilli, "Adeus à escola pública: a desordem neoliberal, a violência do mercado e o destino da educação das maiorias". In: Pablo Gentilli, idem, pp. 228-252.

78 A democracia e a universalização do ensino fundamental 
significados antagônicos, re-significado-as em favor do pensamento ou noções atribuidas historicamente pela esquerda na luta contra o capital. Ao final de tal processo, se conquistaria a hegemonia e se transformaria a realidade social e educacional brasileira. ${ }^{6}$

A re-significação de conceitos e categorias que vem sendo reiteradamente discutida como elemento nucleador da crítica de parte dos educadores vinculados à esquerda precisa, no entanto, ser cuidadosamente avaliada. Categorias como democracia, autonomia, descentralização, participação, cidadania e direitos sociais emergiram na passagem do século XVIII para o XIX. Mas foi ao longo do século XIX que se consolidaram como categorias de análise do pensamento burguês. Na transição do Antigo Regime para o Capitalismo essas expressões encarnaram o significado do processo revolucionário da burguesia, e posteriormente por sua necessidade histórica de se conservar no poder para viabilizar a reprodução do capital. Sendo assim, essas categorias e conceitos permaneceram como dispositivos ideológicos dessa classe, acabando por orientar a luta por direitos da classe proletária que nascia.

É plausível afirmar que essas categorias não se realizaram por serem marcos da promessa burguesa, e nem se realizarão em sua plenitude nas formações sociais capitalistas, sejam elas do capitalismo central ou periférico. No entanto, a validade histórica dessas categorias e sua carga de significado permanecerão até que o capitalismo estiver em vigência. Por essa razão não nos parece possível no plano da realidade objetiva, e mesmo simbólica alterar os significados dessas categorias para alimentar a luta pelo socialismo, pois na medida em que a realidade material for se transformando emergirá novos conceitos e categorias explicativas desta realidade nos impondo outros nomes e outros significados.

E mais, se essas categorias estão prenhes do significado que a burguesia lhes deu, não são os (neo) liberais que estão re-significando-as, e se apropriando indevidamente, ou mesmo roubando nossas históricas bandeiras de lutas, mas sim,é o histórico embate entre capital e trabalho, ao longo da história do capitalismo, que obriga o capital a conceder determinados direitos sociais aos trabalhadores para que as condições da reprodução da mais-valia não sejam colocadas em risco. E fazendo parecer que esta luta e esses conceitos poderiam manifestar o conteúdo do devir da sociedade socialista.

Nesse sentido é possível afirmar que os educadores que fazem a crítica ao pensa-

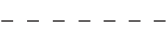

6 Tomáz Tadeu Silva. 0 projeto educacional da nova direita e a retórica da qualidade total. In: Pablo Gentilli, Tomáz Tadeu Silva (orgs.), Escola S.A.: quem ganha e quem perde no mercado educacional do neoliberalismo. Brasília, CNTE, 1996, pp. 167-188.

cadernos cemarx, $n^{0}-2-2005 \quad 79$ 
mento (neo)liberal, herdeiros de uma tradição brasileira que remonta aos anos $20 \mathrm{e}$ 30, estão desde lá tentando teórica e politicamente, perseguir e fazer valer as promessas reconhecidamente liberais que emblematicamente se expressa na luta pela Escola Pública, Gratuita, Laica e Universal. ${ }^{\top}$

O capitalismo seja através de um potente Estado planejador e interventor na economia e na sociedade, isto é, que procure orientar a concorrência e coibir os exageros do monopólio, seja em sua versão pura de livre mercado, onde as leis mercadológicas têm a supremacia econômica sobre a política, o social, o cultural e o espiritual, não resolve a contradição primeira entre capital e trabalho. Portanto, as bases que deram ao liberalismo uma face mais pública e mais sensível às pressões do proletariado, são, em sua versão (neo) liberal, mais reais do que nunca. Pois a desregulação da economia orientada primordialmente pelo mercado só teve sucesso e fincou raízes na medida em que os países na América Latina "enterraram" suas ditaduras; portanto, a forma de governo que parece ser a mais adequada ao (neo)liberalismo é a democracia representativa.

Portanto, a disputa pelo conceito de democracia e seus corolários como autonomia, descentralização, participação e qualidade parecem estar enredando parte da esquerda e provocando um movimento de reflexão teórica e de lutas políticas que, em última instância, não tem contribuído para acirrar as contradições no plano político, e muito menos no plano estrutural. Isto não significa que na história recente do país não tenhamos assistido a intensos e importantes enfrentamentos do movimento organizado dos educadores e outros setores populares com o Estado. Estes embates no plano cultural e político acabaram forçando o poder instituído a implementar alguns projetos reivindicados pelos movimentos, mas que não expressam em sua totalidade as exigências políticas e as orientações teóricas dos educadores. Por essa razão, o movimento dos educadores, apesar de ter reivindicado enfaticamente muitos desses projetos, contraditoriamente não os reconhece como sendo os seus projetos. Tem sido assim com a universalização do ensino fundamental, com o Programa de Classes de Aceleração, com a Promoção Automática, a Participação da Comunidade na Escola, a Bolsa Escola, os Temas Transversais, os Conselhos de Escola etc. ${ }^{8}$

\section{$-\cdots-\cdots$}

7Maria Elizabete Sampaio Prado Xavier. "Para um exame das relações históricas entre capitalismo e escola no Brasil: algumas considerações teórico-metodológicas". Cadernos da Escola Pública - SINPRO, Distrito Federal, noํ1, nov, 1993, pp. 5-23.

8 Ivan Valente e Lisete Arelaro. Progressão continuada X progressão automática. São Paulo, junho 2002 - caderno s/ editora.

80 A democracia e a universalização do ensino fundamental 
Frustração, desencanto, descrédito e, sobretudo, um forte sentimento de traição marcam a forma como a esquerda assiste à implementação de projetos que foram propostos também por ela. Esse conjunto de sentimentos que se materializam em práticas políticas equivocadas, parece ser resultado da crença do ideal de democracia, que não permite a tais educadores a compreenção de que sob essas condições objetivas/subjetivas não é possível realizar plenamente os projetos que contribuiriam para destruir a mitificação da realidade. Portanto, nos parece que essa crença está fundada num pressuposto de caráter idealista. ${ }^{9}$

E por essa razão, queremos reafirmar o entendimento do conceito de democracia da era moderna, portanto, liberal, como uma estratégia capitalista de manutenção de um Estado que garante a realização de seu projeto de classe, qual seja, a reprodução e acumulação do capital em condições adequadas e controláveis. O mesmo movimento que realiza o projeto capitalista, isto é, a expropriação da mais-valia e a ampliação relativa do acesso aos bens tecnológicos e culturais, alimenta a tensão de classes que, em última instância, move a história. Nesse movimento, a democracia tem sido o resultado histórico dessa tensão, e colada à lógica capitalista permite, ora mais ora menos, avanços nas condições de vida das classes trabalhadoras. Por isso, a democracia tem garantido condições objetivas para que este modelo de sociedade se mantenha hegemônico na maioria dos países do planeta, apesar de conviver com crises cíclicas.

Por isso, se a democracia tenciona a acumulação, ela também atende a ajustes fundamentais para a manutenção do status quo capitalista.

Portanto, a democracia que se realiza materialmente em nossa sociedade é a democracia liberal, entendida como a igualdade jurídica, a possibilidade de certa representação política, e o direito ao voto. Mas, objetivamente a democracia está circunscrita ao plano político. Por essa razão é possível inferir que atribuir à democracia um caráter de igualdade material ou é pura ideologia, quando propalada pelos setores dominantes da sociedade, ou idealismo, quando este mesmo entendimento de democracia "embala" as práticas políticas de parte da esquerda. ${ }^{10}$

O projeto de um modelo ideal de sociedade que se realizaria através da democra-

$--\cdots+-$

9 [aio Navarro de Toledo. “As esquerdas e a redescoberta da democracia”. In: Renato Dagnino(org.), Os anos 90:

política e sociedade no Brasil. São Paulo: Brasiliense, 1994, pp. 127-136.

10 Idem, pp. 127-136.

cadernos cemarx, $n ^ { 0 } - 2 - 2 0 0 5 \longdiv { 8 1 }$ 
tização dos níveis social e econômico, além do político, tem levado a crítica de esquerda a uma aposta na democracia como fim último da luta. Essa delimitação da ação no campo democrático tem produzido um distanciamento da possibilidade de apreender o real como estratégia para pensar sua transformação, assim como tem colocado os pensadores de esquerda numa posição mais panfletária que transformadora.

Afinal, ao se entender a democracia como ligada à lógica capitalista, mesmo sem desconsiderar a sua importância para a classe trabalhadora, não garante a sua postulação como um fim, e menos ainda a sua concepção como o caminho para a realização do socialismo.

82 A democracia e a universalização do ensino fundamental 